\title{
Analysis of the effectiveness of therapeutic and prophylactic measures for finger dermatitis of cows
}

\author{
Svetlana Ivanova ${ }^{1, *}$, Vitalina Ivanova ${ }^{2}$, Asgat Mukhitov $^{1}$, and Azat Mukhitov ${ }^{1}$ \\ ${ }^{1}$ Ulyanovsk State Agrarian University named after P.A. Stolypin, 433430, Ulyanovsk, Russia \\ ${ }^{2}$ Mordovia State Pedagogical University named after M.E. Evsevyeva, 430007, Saransk, Russia
}

\begin{abstract}
This article presents the results of comparative studies of the therapeutic efficacy of drugs in the treatment of finger dermatitis in cows on the farm, hematological blood parameters before and after treatment are studied, the main changes in the body of cows after the complex treatment and the clinical picture are considered. Complex treatment in the experimental group showed the greatest therapeutic effect. The beneficial effect of the complex treatment was to stimulate blood counts and the animal's recovery. The optimal method of treatment on the farm is the scheme proposed for the treatment of cows in the experimental group, since this scheme is more effective in therapeutic terms and recovery occurs faster than when using the scheme used at the enterprise.
\end{abstract}

\section{Introduction}

In recent years, Mortellaro's disease, or digital dermatitis, is the most common pathology of the distal part of the extremities of the cows in modern animal husbandry [16]. This disease is not contagious, but significantly compromises the health and productivity of the cattle.

Finger dermatitis of cattle is most often found in dairy cows in highly productive cows, localized on the skin of the interdigital slits in the form of ulcers. Painful lesions cause lameness of varying severity, which leads to a decrease in milk productivity. Currently, there are no data on this disease in the literature, but it is known that it causes significant production losses in dairy cattle due to the loss of milk (due to a decrease in milk yield and milk quality), the costs of treatment and prevention of pathology, and the costs associated with the premature replacement of reproductive animals $[7,8,9]$.

Most often, providing optimal conditions for keeping, feeding and caring for cows leads to recovery, but in industrial cattle breeding this is usually difficult $[10,11]$.

Thus, based on the data provided by many scientific studies, it should be concluded that the danger of this disease and the speed of its spread makes it necessary to carry out all the necessary therapeutic and preventive measures, which should be taken into account in many enterprises and livestock farms.

\footnotetext{
* Corresponding author: sveticiva@rambler.ru
} 
In this regard, the purpose of our work was to find the optimal treatment regimen for finger dermatitis and to analyze the therapeutic effectiveness of the proposed drugs.

\section{Materials and Methods}

The work was carried out in the conditions of the APC (Agricultural Production Cooperative) named after N. K. Krupskaya in the Melekessky district of the Ulyanovsk region. The material of the study was milk cows of a black-and-white Holstein breed, from which two groups of cows with different stages of lesions and the size of ulcerated areas were selected. The treatment was carried out according to the following scheme (table 1).

Table 1. Treatment regimen in the experimental and control groups.

\begin{tabular}{|c|c|}
\hline \multicolumn{2}{|c|}{ Animal groups } \\
\hline Experimental & Control \\
\hline $\begin{array}{c}\text { Terramycin Aerosol Spray, } \\
\text { Oxytocin Powder 20 }\end{array}$ & $\begin{array}{c}5 \% \text { solution of copper sulfate, } \\
\text { daily, for 5 days }\end{array}$ \\
\hline
\end{tabular}

For hematological studies, blood samples were taken from animals affected by the disease. Whole blood was collected from the tail vein into $9.0 \mathrm{ml}$ vacuum tubes with a clot activator. For the formation of a clot, the tubes with blood were left at room temperature for 2 hours.

Morphological studies were carried out on an automatic hematological veterinary analyzer PCE-90-Vet: the number of erythrocytes and the content of hemoglobin. On the analyzer AKBa-01 BIOM, the level of total protein, albumin, $\alpha-, \beta-, \gamma$-globulins was determined. Leukocytes were determined by counting in a Goryaev chamber. To calculate the leukogram, blood smears were prepared and stained according to Romanovsky-Giemsa.

The research results obtained during the experiment were analyzed in the computer program Statistica 6.0.

\section{Results and Discussion}

The formed control group was treated by running through baths filled with a $5 \%$ solution of copper sulfate daily for five days. Baths with the solution were located at the entrances and exits of the milking parlor. The solution was changed after 400 cattle passed through it. No additional treatment was applied to animals from this group. Control of the condition of the animals was carried out 2 times, taking into account the break, for a period of 2 weeks.

The experimental group of cows after trimming the hoof horn was cleaned of the limb from the accumulation of manure and dirt, and the formation was opened with a hoof knife. Next, the limbs were dried with a construction hair dryer to burn only the wool and hair, with a hoof knife, all the tissue affected by necrosis was removed, the entire upper layer until a smooth, clean wound surface remained. The bandage was used to clean off all secretions, blood clots, and the remains of rotting tissues. After the wound was treated with an aerosol preparation Terramycin; lesions occurring in the interdigital fissure were cauterized with Oxycin 20 powder, followed by a bandage on the limb. The wounds were dried again, to a dull skin color-an indicator was that the entire surface of the hoof was sufficiently dried. Bandages were applied exactly to the site of the lesion, the bandage was twisted with an eight at each turn so that the powder did not fall out when the limb moved, then, when the bandage was applied, it was fixed with medical tape. After three days, the bandages were removed and examined in case of a relapse. 
At the end of 14 days after the start of treatment, we re-examined the condition of the limbs of both groups of cows. In the process of using baths in the control group with a 5\% solution of copper sulfate according to the scheme adopted in the farm, one animal with the M3 stage had a complete recovery, in 2 animals the condition of the lesion remained unchanged. Despite this, out of 3 heads, one cow's lameness index decreased by a point, and one, on the contrary, the degree of lameness increased by a point, along with an increase in the size of the ulcer by $3 \mathrm{~mm}$. It should be noted that the pathological process of the disease in the majority of cows from the group ( 2 out of 3 heads) did not change in the future, and, quite possibly, at the end of treatment only worsened, despite the therapeutic effect of baths with a disinfectant solution of copper sulfate. It is also necessary to pay attention to the fact that only one animal has passed the stage of recovery, which is only $33.3 \%$ of the entire group.

In the experimental group, after the use of the drugs Oxytocin 20 and Terramycin, all indicators improved. In all three cows, there was a change in ulcerative lesions in a less intense direction - from M4 to M3 in one cow and a transition from M2 to M3 in the remaining cows. Since bandages were applied to the animals, and, consequently, their condition needed to be monitored, it was decided to examine the group again on day 16 .

During the final study, it was found that one cow had a regeneration of the cover on the site of the affected area, and the other heads had a dark scab on the affected area. In general, in the course of treatment, the extinction of the infectious process was observed, which was expressed in a decrease in general indicators: a decrease in the diameter of ulcers, the degree of lameness and pain sensitivity.

The results of the analysis of the blood serum of cows diagnosed with Mortellaro showed that before treatment, cows had an increase in white blood cells $(12.8 \pm 1.45 \mathrm{~g} / \mathrm{l})$ and the content of segmental neutrophils $(36.5 \pm 0.52 \mathrm{~g} / \mathrm{l})$, a decrease in red blood cells $(4.5$ $\pm 0.18 \mathrm{~g} / \mathrm{l})$ and hemoglobin $(95.2 \pm 0.05 \mathrm{~g} / \mathrm{l})$ in the blood of animals. Indicating the development of an inflammatory process in the animal's body.

Treatment of cows in the experimental and control groups led to an increase in blood hemoglobin up to $112.0 \pm 0.13 \mathrm{~g} / \mathrm{l}$ and $99.0 \pm 0.22 \mathrm{~g} / \mathrm{l}$, that is by $17.6 \%$ and $4.0 \%$; an increase in erythrocytes to $6.5 \pm 0.03 \mathrm{~g} / 1$ and $5.8 \pm 0.04 \mathrm{~g} / \mathrm{l}$, that is by $44.4 \%$ and $28.8 \%$ (figure 1), respectively, by groups, relative to background values. But these data were considered not reliable. Such changes indicate an increase in redox reactions and the activation of metabolic processes in the body of animals.

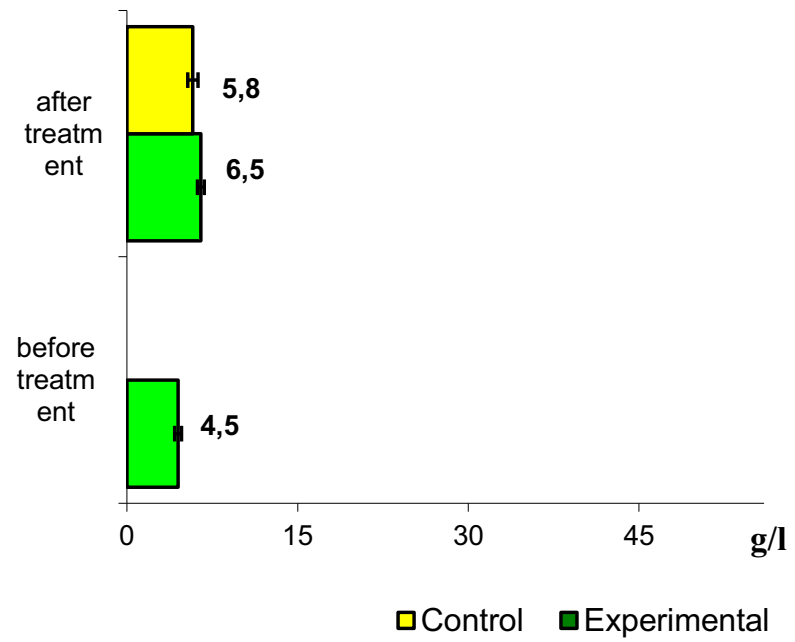

Fig. 1. Concentration of erythrocytes in the blood of animals before and after treatment. 
Also, after treatment, the level of white blood cells decreased (figure 2) in the experimental group to $11.8 \pm 0.93 \mathrm{~g} / \mathrm{l}$ and in the control group to $11.9 \pm 0.12 \mathrm{~g} / \mathrm{l}$, that is by $7.8 \%$ and $7.0 \%$, which indicated a favorable course of the inflammatory process and recovery of animals in both groups. All this, apparently, was due to the complex effect of drugs on the general condition of the animals, on the activation of functional activity, which subsequently led to the recovery of the animals.

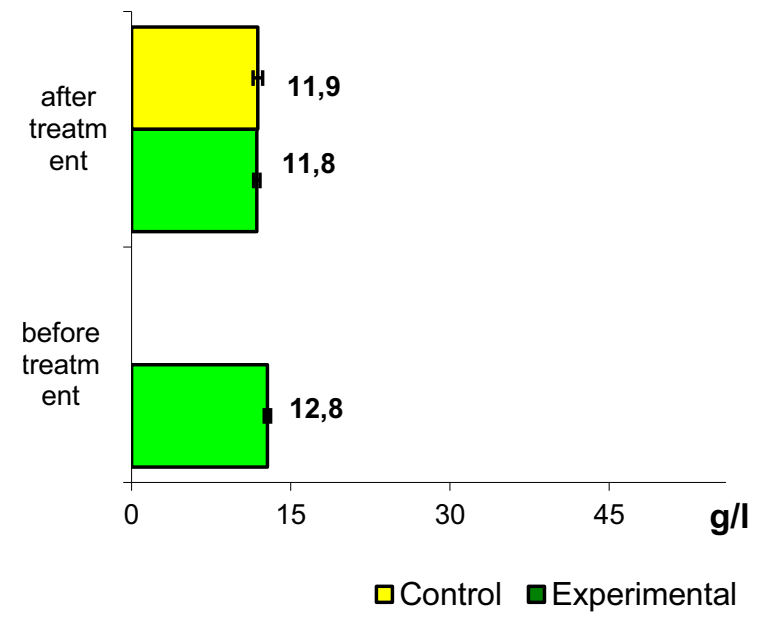

Fig. 2. The content of hemoglobin in the blood of animals before and after treatment.

In addition, the use of these drugs contributed to the restoration of the number of segmented neutrophils (figure 3) to $31.0 \pm 0.44 \mathrm{~g} / 1$ and $30.2 \pm 0.54 \mathrm{~g} / 1$, that is by $15.0 \%$ and $17.2 \%$, which indicated the termination of the acute form of the course of the infectious process.

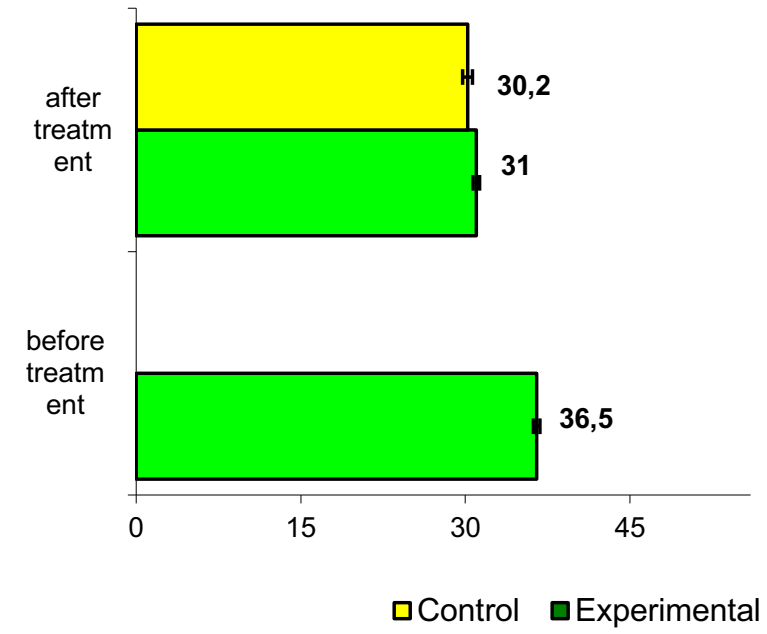

Fig. 3. The number of segmented neutrophils in the blood of animals before and after treatment.

The results of the analysis of protein metabolism at the beginning of the experiment showed that the amount of total protein in the experimental animals did not exceed the physiological norm and the average for the groups was $78.0 \pm 0.80 \mathrm{~g} / \mathrm{l}$. After treatment, a decrease relative to the background was noted in the control group by $1.8 \%$, and in the experimental group it slightly increased by $1.5 \%$. But this data was not considered reliable. 
The background values for the albumin content (figure 4) varied within the standard limits and averaged $32.6 \pm 0.43 \%$ for the groups, and after treatment they increased in both groups - by $0.9 \%$ and $1.8 \%$. The dynamics of the albumin concentration tended to increase. Thus, the concentration of albumins in the blood serum, relative to the background, increased in both groups - by $0.9 \%$ and $1.8 \%$, respectively. The increase in blood immunoglobulin levels indicated an improvement in metabolism and an increase in the immunobiological response of the body of cows.

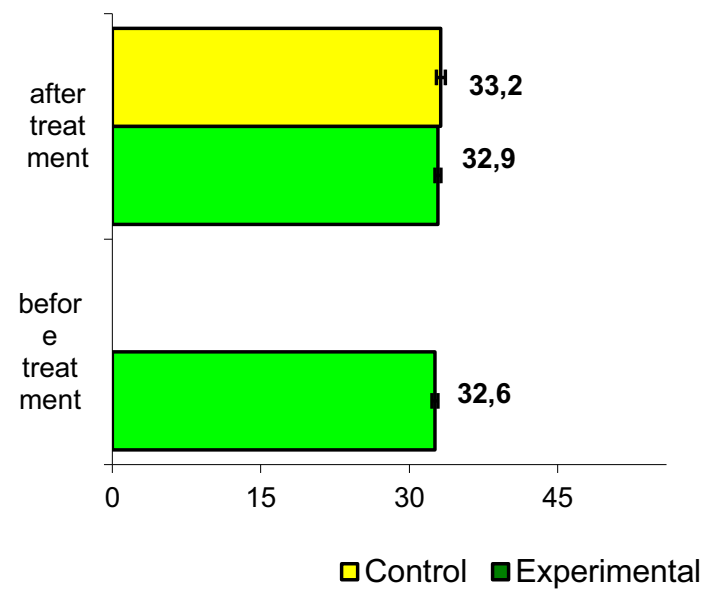

Fig. 4. The amount of albumin in the blood of animals before and after treatment.

The concentration of gamma-globulins in the experimental animals at the beginning of the experiment was reduced and averaged $13.1 \pm 0.60 \%$ (figure 5). After treatment, yglobulins tended to decrease in both groups. Thus, there was a decrease in the experimental and control groups by $18.4 \%$ and $14.6 \%$, respectively.

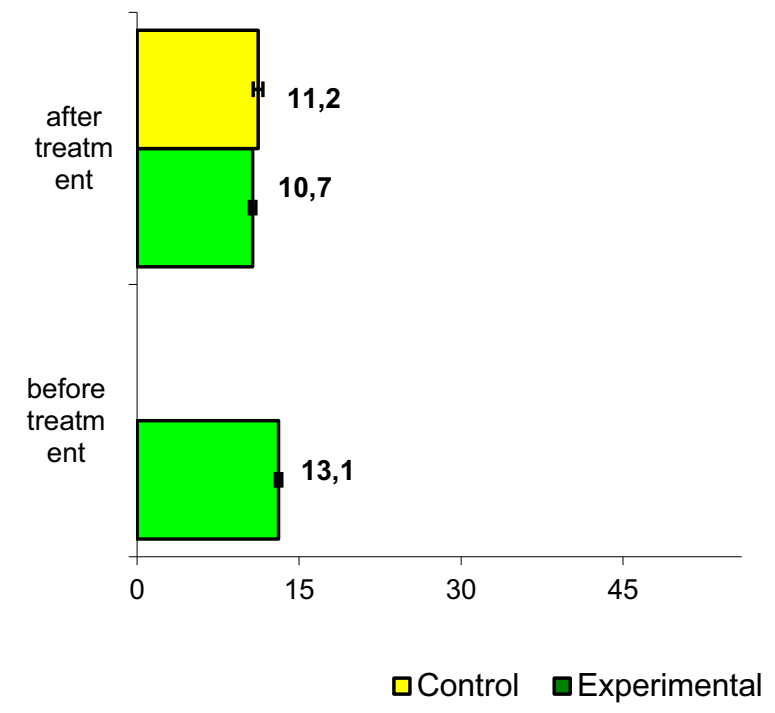

Fig. 5. The concentration of gamma-globulins in the blood of animals before and after treatment.

Also, after the start of treatment, an increase in nitrogen in the blood was noted: its share was $23.0 \%$ higher than the previous indicator and $30.0 \%$ higher than in the control 
group. The use of Oxycin in combination with Terramycin had a positive effect on all serum parameters.

The prescribed treatment also prevented the excessive consumption of vitamin $\mathrm{E}$ (one of the important elements in the animal's body). The level of vitamin $\mathrm{E}$ in the control group exceeded the norm by $22.0 \%$. This has greatly affected the immune system of dairy animals and the recovery process.

At the end of treatment, a certain stabilization of a number of indicators was noted in the experimental group, which contrasted with the indicators of the control group, where the number of globulins rapidly decreased, and the difference was $65.0 \%$. It should also be noted that the percentage of vitamin $\mathrm{E}$ did not decrease in the control group during treatment.

The obtained results of hematological data showed that there was a weak resistance of the cattle body due to the impact of seasonal stress conditions, which contributed to an increase in the incidence of finger dermatitis (Mortellaro), diagnosed in the livestock of the farm, but the use of modern medicines contributed to the improvement of the immunobiological status of the experimental cattle and further recovery.

\section{Conclusion}

Based on the above data, it should be concluded: in order to prevent the spread of the disease throughout the livestock, veterinary specialists should examine the limbs as often as possible for the first signs of the disease, as well as immediately begin treatment of ulcerative formations in the initial stages.

The results of a comparative assessment of the efficacy of veterinary drugs in both groups showed that in the control group there was an insignificant percentage of recovery, although one head had a final recovery from the M3 stage. Nevertheless, this treatment regimen had a therapeutic and prophylactic effect, this is noticeable in a decrease in the sum of points of one animal and in the absence of changes of two animals.

In the experimental group, the use of Oxytocin 20 drugs in combination with the aerosol drug Terramycin led to an improvement in all indicators and a decrease in the comprehensive assessment of lesions. All three animals in the group had scab formation at the site of ulcers, which is a necessary condition for the recovery process.

The use of treatment for finger dermatitis in cows in the experimental group showed better results in clinical and morphological parameters of blood, compared with the control group. The positive effect of the drugs on blood parameters was to stimulate erythropoiesis, increase the level of hemoglobin, as well as reduce the number of white blood cells and segmental neutrophils.

Thus, the optimal method of treatment on the farm is the scheme proposed for the treatment of cows in the experimental group, since this scheme is more effective in therapeutic terms and recovery occurs faster than when using the scheme used in the enterprise.

\section{References}

1. C. A. Rodrigues, C. A. Hussni, E. S. Nascimento, C. Esteban, S. H. V. Perri, J. vet. Pha rmacol. Therap, 33, 363 (2009)

2. S. V. Fedotov, V. S. Avdeenko, N. S. Belozercheva, I.M. Yahaev, Reproduction in do mestic animals, 54 (3), 138 (2020)

3. V. V. Zemlyankin, I. V. Nenashev, J. Vestnik of Ulyanovsk State Agricultural Academ y, 1(41), 86 (2018) 
4. A. P. Finogenova, S. N. Ivanova, V. A. Ermolaev, N. Yu. Terentyeva, Scientific notes of the Kazan state academy of veterinary medicine named after N.E. Bauman, 245 (1), 199 (2021)

5. D. Döpfer, M. Holzhauer, M. van Boven, The Veterinary Journal, 193, 648 (2012)

6. M. Holzhauer, C. Bartels, D. Döpfer, G. van Schaik, The Veterinary Journal, 177, 222 (2008)

7. L. N. Cosolovich, S. N. Ivanova, J. Vestnik of Ulyanovsk State Agricultural Academy, 1 (21), 83 (2013)

8. S. V. Polyakov, N. Yu. Terentyeva, S. N. Ivanova, Vestnik of Ulyanovsk State Agricul tural Academy, 4 (52), 128 (2020)

9. E. O. Saitkhanov, D. S. Besedin, A.V. Ore, Vestnik RGATU, 3, 62 (2018)

10. M. N. Britan, K. A. Gerceva, E. V. Kiseleva, V. V. Kulakov, Eh. O. Saytkhanov, R. S. Soshkin, International Journal of Pharmaceutical Research, 11 (1), 1040 (2019)

11. J. Hernandez, J. K. Shearer, J. B. Elliot, Am. Vet. Med. Assoc, 214, 688 (1999) 